\title{
Clinical potential of methylphenidate in the treatment of cocaine addiction: a review of the current evidence
}

This article was published in the following Dove Press journal:

Substance Abuse and Rehabilitation

17 June 2015

Number of times this article has been viewed

\author{
Kenneth M Dürsteler ${ }^{1,2}$ \\ Eva-Maria Berger' \\ Johannes Strasser' \\ Carlo Caflisch ${ }^{2}$ \\ Jochen Mutschler ${ }^{2}$ \\ Marcus Herdener ${ }^{2}$ \\ Marc Vogel' \\ 'Center for Addictive Disorders, \\ Psychiatric University Clinics Basel, \\ Basel, Switzerland; ${ }^{2}$ Center for \\ Addictive Disorders, Department \\ of Psychiatry, Psychotherapy and \\ Psychosomatics, Psychiatric Hospital, \\ University of Zurich, Zurich, \\ Switzerland
}

Background: Cocaine use continues to be a public health problem, yet there is no proven effective pharmacotherapy for cocaine dependence. A promising approach to treating cocaine dependence may be agonist-replacement therapy, which is already used effectively in the treatment of opioid and tobacco dependence. The replacement approach for cocaine dependence posits that administration of a long-acting stimulant medication should normalize the neurochemical and behavioral perturbations resulting from chronic cocaine use. One potential medication to be substituted for cocaine is methylphenidate (MPH), as this stimulant possesses pharmacobehavioral properties similar to those of cocaine.

Aim: To provide a qualitative review addressing the rationale for the use of MPH as a cocaine substitute and its clinical potential in the treatment of cocaine dependence.

Methods: We searched MEDLINE for clinical studies using MPH in patients with cocaine abuse/ dependence and screened the bibliographies of the articles found for pertinent literature.

Results: MPH, like cocaine, increases synaptic dopamine by inhibiting dopamine reuptake. The discriminative properties, reinforcing potential, and subjective effects of MPH and cocaine are almost identical and, importantly, MPH has been found to substitute for cocaine in animals and human volunteers under laboratory conditions. When taken orally in therapeutic doses, its abuse liability, however, appears low, which is especially true for extended-release MPH preparations. Though there are promising data in the literature, mainly from case reports and open-label studies, the results of randomized controlled trials have been disappointing so far and do not corroborate the use of MPH as a substitute for cocaine dependence in patients without attention deficit hyperactivity disorder.

Conclusion: Clinical studies evaluating MPH substitution for cocaine dependence have provided inconsistent findings. However, the negative findings may be explained by specific study characteristics, among them dosing, duration of treatment, or sample size. This needs to be considered when discussing the potential of MPH as replacement therapy for cocaine dependence. Finally, based on the results, we suggest possible directions for future research.

Keywords: agonist replacement, dependence, substitution

\section{Introduction}

Since the 1980s, the use of cocaine has emerged as a significant public health problem globally. According to the United Nations Office on Drugs and Crime (UNODC), in 2012 there were 17 million cocaine users (range 13-20) worldwide. ${ }^{1}$ Cocaine has been estimated to be the second most used illicit drug in North and South America, the Caribbean, Southern Africa, and Western and Southern Europe. ${ }^{2,3}$ In Europe, cocaine is the most popular illicit stimulant drug. It is estimated that approximately 2.2 million young adults aged $15-34$ years (1.7\% of this age group) used cocaine in the last year. ${ }^{3}$
Correspondence: Kenneth M Dürsteler Center for Addictive Disorders, Psychiatric University Clinics Basel, Wilhelm Klein-Strasse 27,

4012 Basel, Switzerland

Tel +4I 613255125

Fax +4I 6I 3255364

Email kenneth.duersteler@upkbs.ch 
However, as elsewhere in the world, there is great variability across Europe; high estimates of cocaine use are restricted to a number of countries, with UK, Spain, Ireland, the Netherlands, and Denmark ranking at the top concerning prevalences of lifetime and past-year cocaine use. ${ }^{3}$ Wastewater analyses from 42 cities also revealed large regional differences in cocaine use in Europe. ${ }^{4}$ Considering longer-term trends in cocaine use, declines have been observed after a peak in 2008 for most European countries, especially for those where cocaine use is widespread. ${ }^{3}$

Cocaine use is associated with a variety of psychiatric conditions and with negative physical and psychosocial consequences. ${ }^{5}$ Among others, these include cardiovascular and neurological disorders, psychotic symptoms, bloodborne infections (eg, HIV, HBV, HCV), unintentional injuries, violent behaviors, and premature death. ${ }^{6-12}$ According to epidemiological data, cocaine users show a four-to-eight times higher mortality rate than their age-sex peers in the general population. ${ }^{13}$ Although many consumers use cocaine occasionally, some develop a more compulsive pattern of use and become dependent on cocaine. It has been estimated that $6 \%-7 \%$ of those who use cocaine for the first time will develop a dependence syndrome within the first year of use and about one-fifth will meet dependence criteria by the age of 45 years. ${ }^{14}$ Cocaine dependence is a chronic mental disorder characterized by high rates of relapse, which may occur after many months or even years of abstinence. It has a significant impact because of its onset in younger age and contributes substantially to burden of disease. ${ }^{15}$ Cocaine accounts for a substantial proportion of treatment admissions for substance use disorders. According to the European Monitoring Centre for Drugs and Drug Addiction (EMCDDA), cocaine was cited as the primary drug for $14 \%$ of all reported persons entering specialized drug treatment in $2012(55,000)$, and $18 \%$ of those entering treatment for the first time $(26,000){ }^{3}$ Differences exist between countries, with approximately $90 \%$ of all cocaine patients being reported by Germany, Spain, Italy, the Netherlands, and the UK, which account together for just over half of the EU population.

Comorbid attention deficit hyperactivity disorder (ADHD) is common among cocaine-dependent patients, and substance-using patients in general. ${ }^{16,17}$ Furthermore, substance use is prevalent in parents of children with ADHD, ${ }^{18}$ and children of substance-using adults are at an elevated risk for ADHD. ${ }^{19}$ Dopaminergic deficits as well as executive dysfunction have been demonstrated in both disorders, ${ }^{20,21}$ which may share common genetic risk factors. ${ }^{22}$
Individuals may also, at least initially, use cocaine as selfmedication for symptoms related to ADHD. ${ }^{23}$

\section{Current status of treatment for cocaine dependence}

The treatment of cocaine dependence still remains a great challenge. After almost 3 decades of intense research, there is no well-established effective medication available, nor is any medication approved for cocaine dependence by any medication's regulatory authority. The primary interventions with evidence of efficacy are behavioral approaches. For instance, contingency management (CM) which provides incentives (eg, vouchers, cash) for drug-free urine samples or other desired behaviors (eg, treatment attendance) has proven effective in reducing cocaine use and fostering abstinence during treatment, even in difficult-to-treat patients. ${ }^{24,25}$ However, it is not clear whether CM leads to long-term abstinence, as its effects tend to subside after treatment. ${ }^{24,26}$ Another effective intervention for patients committed to reducing or eliminating their cocaine use is cognitive-behavioral therapy (CBT). ${ }^{27,28}$ Its goal is abstinence through functional analysis of high-risk situations for cocaine use and the development of effective coping strategies through skills training. Yet, the impact of behavioral approaches is limited for several reasons. Among others, they require substantial investments in care delivery systems and trained professionals to implement the interventions. ${ }^{29}$ Moreover, cognitively more demanding interventions, such as CBT, do not suit all patients, ${ }^{30,31}$ and patient commitment is important for CBT success. ${ }^{32-34}$ Overall, behavioral treatments alone have moderate effect sizes in terms of abstinence and retention, ${ }^{27,28,35}$ underscoring the continuing need for effective pharmacotherapies for cocaine dependence. ${ }^{27,36}$

One plausible pharmacotherapeutic approach to treat cocaine dependence is agonist-replacement, or substitution, therapy, which is already effectively used in the treatment of opioid $^{37,38}$ and tobacco ${ }^{39,40}$ dependence. As the term implies, a pharmacologically similar agent is thereby substituted for the abused substance with the goal to reduce the cycle of compulsive substance use and its associated harms. This qualitative review addresses the rationale for the use of methylphenidate (MPH) as a substitution medication and its clinical potential for the treatment of cocaine dependence.

\section{Methods}

We performed a MEDLINE search using the following key terms (all without quotation marks): "cocaine use", "treatment", all in combination with the term "methylphenidate" 
and the Boolean operator "AND". The search produced 144 results published from 1965 through September 2014. Two of the authors also scanned the references of the studies to identify additional citations that were not captured in the search. For the review, we included studies on treatment of patients with cocaine abuse/dependence with MPH to improve cocaine use. With this strategy, we identified eight case reports/open-label studies and six randomized controlled studies. In addition, we selectively considered preclinical and human laboratory data where appropriate.

\section{Rationale for MPH as a potential substitute for cocaine}

The replacement approach for cocaine dependence posits that substitution with a cross-tolerant agent may suppress cocaine craving and withdrawal symptoms and/or block the euphorigenic effects of cocaine. ${ }^{41,42}$ Ideally, such a compound would mimic the positive effects of cocaine without inducing craving, ie, should likely have a slow onset and long duration of action to minimize drug abuse liability. ${ }^{41,43}$ However, substitution therapies may also function as positive reinforcers and can therefore be used as reinforcing stimuli in $\mathrm{CM}$ strategies to decrease cocaine use and promote more adaptive behaviors. ${ }^{44}$

A valid target for a cocaine substitute is the dopamine system, as cocaine is thought to exert its reinforcing properties primarily by blockade of the presynaptic dopamine transporters. ${ }^{45}$ This inhibits dopamine reuptake, elevating extracellular dopamine levels within the mesolimbic "reward" system, especially in the nucleus accumbens. ${ }^{45-47}$ While acute inhibition of dopamine uptake by cocaine consistently results in increased dopamine activity, chronic cocaine intake leads to dysregulation of striatal dopamine signaling. ${ }^{4-50}$ Compounds that directly or indirectly modulate dopamine to reverse alterations associated with cocaine use may therefore prove beneficial as treatment agents. ${ }^{51}$ However, though likely necessary, enhancement of the dopamine system may not be sufficient to treat cocaine dependence, ${ }^{52,53}$ as other neurotransmitter systems such as serotonin and norepinephrine mediate the reinforcing effects of cocaine. ${ }^{54}$

\section{MPH}

MPH, a piperidine derivate, was first synthesized in 1944 and marketed by Ciba-Geigy Pharmaceutical Company as Ritalin. ${ }^{55}$ Initially indicated for various conditions (eg, chronic fatigue, depressive states, disturbed senile behavior, or psychosis associated with depression), ${ }^{56} \mathrm{MPH}$ is mainly used today for the treatment of ADHD and, to a lesser extent, sleep disorders (eg, excessive daytime sleepiness, narcolepsy). ${ }^{42}$ When used as indicated, this stimulant drug is well tolerated and remarkably safe with a minimal side effect profile as demonstrated in disparate patient populations, ${ }^{56,57}$ especially also in those with ongoing cocaine use. ${ }^{31,58-60} \mathrm{In}$ line with the stimulant-like effect profile of MPH, common side effects include insomnia, decreased appetite, dry mouth, increased heart rate, headache, nervousness, nausea, and dizziness. ${ }^{31,55}$ Where potentially more serious side effects occur, they have been found to be reversible with dose reduction or drug discontinuance. ${ }^{56,61}$ Today, various immediate-release (IR) and sustained-release (SR) preparations of MPH are available under several brand names in multiple forms for oral and transdermal administration.

It is well established that MPH enhances cognitive performance not only in individuals with ADHD or those who have suffered traumatic brain injury, but also in healthy human volunteers, eg, on tasks that are sensitive to frontal lobe damage. 56,62,63 In line with this, MPH has been found to improve higher-order aspects of neurocognitive functioning in cocaine-dependent individuals. ${ }^{63-65}$ This suggests that MPH therapy could potentially reverse neural alterations and cognitive deficits resulting from chronic cocaine use, thereby making patients more amenable to behavioral interventions. ${ }^{66}$ The wake-promoting properties may also be positive in cocaine-using individuals, in particular regarding the known deterioration in sleep architecture associated with acute cocaine abstinence. ${ }^{67}$

However, MPH, like amphetamine and cocaine, can also elicit reinforcing effects and tolerance. Thus, it has the potential for abuse, misuse/diversion, and dependence, which limits its clinical use. ${ }^{68-70}$ While its abuse potential appears low when administered as indicated, which is especially the case for SR formulations, the misuse and diversion of MPH seems a more widespread problem. ${ }^{71-73}$ Usually, this misuse is associated with efforts to increase concentration and attention, often in competitive academic environments. ${ }^{74,75}$

\section{Neurochemical profile of MPH}

Although MPH is structurally related to amphetamine, the two stimulants differ in their neurochemical mechanisms of action. ${ }^{76}$ Amphetamine causes dopamine release into the synaptic cleft and secondarily blocks catecholamine reuptake. ${ }^{77-79}$ In contrast, $\mathrm{MPH}$, like cocaine, acts as a monoamine reuptake inhibitor; it binds to presynaptic dopamine and noradrenaline transporters, thereby increasing the extracellular catecholamine concentrations. ${ }^{45,80-82}$ However, the monoaminergic pharmacology of MPH and 
cocaine is profoundly different from that of conventional monoamine reuptake inhibitors (eg, bupropion, mazindol). ${ }^{83}$ Based on a wealth of data, Heal et $\mathrm{al}^{83}$ have recently concluded that the unusual, stimulant profile of MPH and cocaine is not mediated by reuptake inhibition alone. They propose that MPH allosterically modulates the function of the dopamine reuptake transporter to reverse its direction of transport, resulting in a firing-dependent retrotransport of dopamine into the synaptic cleft. Cocaine and MPH may therefore act as "inverse agonists" of the dopamine transporter (DAT), and this mechanism may be the major contributor to their pharmacobehavioral actions, especially when given at high doses and by routes that promote rapid entry into the brain.

Although the exact mechanism by which cocaine and MPH exert their euphorigenic effects is not fully clear, brain imaging studies have shown that both drugs are very similar in terms of their action at the DAT. ${ }^{84-86}$ When administered intravenously, the in vivo potency of MPH at the DAT in the human brain is equivalent to that of cocaine. ${ }^{87}$ Moreover, the spatial and temporal distributions of intravenous (iv) MPH in the human brain are almost identical to those of iv cocaine, with the striatum showing the highest concentrations and time to reach peak uptake corresponding to 2-10 minutes for both drugs. ${ }^{88}$ Although the effects of iv MPH and cocaine overlapped considerably in that latter study, the two drugs differed markedly in their pharmacokinetics. The peak concentration of MPH in the brain was maintained for 15-20 minutes, whereas for cocaine it was maintained only for 2-4 minutes. MPH also cleared much more slowly from the striatum than did cocaine, with half-peak clearance of MPH taking about four to five times longer than that of cocaine (20 minutes). For both drugs, the fast uptake in the striatum paralleled the "high" experience but only for cocaine did the decline in the "high" correspond to the brain clearance rate. In contrast, for MPH, the "high" decreased as rapidly as for cocaine despite significant striatal binding of the drug, suggesting that acute tolerance to the reinforcing effects of MPH had occurred. The slow brain clearance of MPH may therefore limit its abuse potential, which would be favorable for a cocaine substitute. ${ }^{89}$ However, study data indicate that even when $80 \%$ of the DAT sites are occupied by MPH, this blockade does not prevent the subsequent "high" induced by a second iv injection of MPH given 60 minutes later. ${ }^{90}$

According to the rate hypothesis, the strength of euphorigenic effects is proportional to the rate of drug binding to its site of action; thus, routes of administration which produce faster brain uptake are more reinforcing. ${ }^{91} \mathrm{MPH}$ has been found to be up to 100 -fold more potent when administered intravenously than orally. ${ }^{83}$ In brain imaging studies that evaluated the relationship between MPH-induced dopamine increases and their reinforcing effects when equivalent levels were established for iv and oral MPH, only iv MPH elicited a "high".92,93 The peak level of DAT blockade for clinically relevant doses of $\mathrm{MPH}$, although delayed at approximately 1 hour, was about the same as that observed with iv MPH that induced a "high". ${ }^{94}$ However, even when doses of iv MPH are administered that produce significant DAT blockade, they are not always perceived as reinforcing, suggesting that DAT blockade, although necessary, is not sufficient to produce the "high". 92

\section{Behavioral effects profile of MPH}

Preclinical and human laboratory studies suggest that the stimulant-like behavioral effects of MPH are virtually indistinguishable from those induced by cocaine when both drugs are delivered by the same route of administration. For example, both drugs function as reinforcers in animals and humans under a variety of laboratory conditions. ${ }^{68}$ When delivered intravenously, MPH, like cocaine, maintains high rates of operant responding in rats, and long access to MPH results in an escalation of intake similar to cocaine. ${ }^{95}$ Injections of iv MPH also sustain self-administration in squirrel monkeys. ${ }^{96}$ Furthermore, drug discrimination studies in rodents indicate that MPH at higher doses fully substitutes for the cocaine cue..$^{52,97}$ In laboratory studies examining the reinforcing effects of cocaine in rats pretreated with intraperitoneal MPH, higher doses of MPH decreased cocaine intake but not responding to cocaine. ${ }^{97}$ However, 8-month treatment with oral MPH significantly reduced the rates of cocaine self-administration in rodents, suggesting that $\mathrm{MPH}$ pretreatment may alter cocaine reinforcement. ${ }^{98}$

With respect to the euphorigenic properties of MPH, subjective-effects studies of oral MPH in human adults have provided mixed results. In some studies, single doses up to $60 \mathrm{mg} \mathrm{MPH}$ tended to increase ratings of activity, arousal, concentration, intellectual efficiency, energy, anxiety, and talkativeness in healthy volunteers with no history of substance dependence, but not those of "drug liking", "euphoria", or "high". ${ }^{94,99,100}$ Other studies, in contrast, found increased ratings of "good effects" and "drug liking" in non-drug-using volunteers after administration of oral MPH 40 mg. ${ }^{.1101-103}$ However, SR formulations of MPH are associated with less or lower ratings of "good effects" as compared to the IR formulation. ${ }^{71}$

In laboratory studies with cocaine-experienced volunteers, oral MPH 15-90 mg also produced ratings of "drug liking" and "stimulation" similar to those reported for oral cocaine. ${ }^{104}$ Moreover, single doses of intranasally administered MPH 
$(10,20,30 \mathrm{mg})$ yielded dose-dependent increases in ratings of "good effects" and "high" in recreational stimulant users. ${ }^{105}$ After injections of iv MPH $(0.5 \mathrm{mg} / \mathrm{kg})$, both drug-naïve and cocaine-using volunteers experienced a "high". ${ }^{106}$ Cocaine users reported that the "high" induced by iv MPH was similar to that of iv cocaine but lasted longer and was associated with more physical effects, ie, "stimulated more the body than the brain". ${ }^{106} \mathrm{MPH}$ injections also consistently induced cocaine craving in these cocaine users, while, in another experiment, oral IR MPH doses up to $60 \mathrm{mg}$ increased neither cocaine craving nor subjective ratings that could suggest abuse potential in cocaine-dependent participants. ${ }^{107}$ Furthermore, oral $\mathrm{MPH}$ in supratherapeutic doses was found to generalize to the cocaine cue in cocaine users who have been trained to discriminate between placebo and $200 \mathrm{mg}$ oral cocaine; relatively high rates of cocaine-appropriate responding were also observed with MPH 30 mg. ${ }^{104}$

In two human laboratory studies assessing the effects of MPH treatment on iv cocaine, ${ }^{58,60}$ cocaine-dependent volunteers with and without adult ADHD were maintained on 0,40 , and $60 \mathrm{mg} /$ day or on 0,60 , and $90 \mathrm{mg} /$ day oral SR MPH. Both of these studies included a fixed cocaine dosing schedule. During each maintenance phase, a dose-response function was determined for iv cocaine (0-50 mg). Maintenance on MPH significantly attenuated cocaine-induced increases in "good effects" and "desire for cocaine" ratings; these effects, however, were limited to the lower cocaine doses. In addition to the fixed dosing of cocaine, the first of these studies also included a choice experiment, in which seven cocaine-dependent patients with concomitant ADHD were maintained on 0 , 40 , and $60 \mathrm{mg} /$ day oral SR MPH. ${ }^{58}$ The reinforcing effects of iv cocaine $(0,16$, and $48 \mathrm{mg} / 70 \mathrm{~kg})$ were assessed using a procedure wherein participants sampled a dose of iv cocaine (16 or $48 \mathrm{mg} / 70 \mathrm{~kg}$ ) and were then given five opportunities to choose between it and two tokens, each exchangeable for US\$2. As compared to placebo treatment, substitution with $60 \mathrm{mg}$ /day MPH reduced the choice of the higher iv dose significantly from four to two times.

Overall, clinical laboratory studies largely support MPH as a treatment for cocaine addiction. To our knowledge, however, there are no studies on how cocaine users experience $\mathrm{MPH}$ in naturalistic settings.

\section{Clinical studies on MPH as a substitute for cocaine}

A number of case reports, open-label studies, and controlled trials have addressed the clinical potential of $\mathrm{MPH}$ for the treatment of cocaine dependence in various patient populations (Table 1).

\section{Case reports}

Khantzian ${ }^{23}$ was the first to report a case of a woman who presented a childhood history suggestive of ADHD and whose chronically excessive cocaine use was endangering her life. He started her on MPH $15 \mathrm{mg}$ three times per day (tid) after a 6-day cocaine binge that had ended only 5 hours prior to her therapy appointment. Within 1 day, she began to experience normal appetite and sleep. Her mood had improved significantly and her cocaine craving had disappeared. She experienced one minor relapse in the first year as confirmed by urinalysis and continued weekly therapy sessions. A 2-year follow-up of this patient was presented 1 year later as the case of "Mrs B" in a series of case reports ${ }^{108}$ that described three cocaine-dependent patients who shortly after beginning treatment with MPH showed a reduction in cocaine use. Medication was started at $15 \mathrm{mg}$ tid in two patients and $5 \mathrm{mg}$ four times per day in one patient. Doses were then increased up to a maximum of $70 \mathrm{mg} /$ day. All three patients remained abstinent from cocaine for at least several months up to 2 years. Moreover, MPH improved symptoms of depression in one patient; in another, enhanced concentration and less violent behavior was stated; and, in the third patient, agitation, compulsive gambling, and interest in pornography decreased. The authors concluded that these cases lent support to the self-medication hypothesis of Khantzian. ${ }^{23}$ This hypothesis posits that an individual's choice to use a particular drug depends to some degree on the drug's effect on subjective painful affects or unpleasant emotional states which may or may not be associated with a psychiatric disorder. ${ }^{23}$

Two other successful case reports have appeared more recently. Imbert et $\mathrm{al}^{109}$ report the case of a male patient with cocaine dependence and adult ADHD who was also addicted to gambling and compulsive sex. Medication with the aim of improving ADHD symptoms and cocaine dependence was started with SR MPH $18 \mathrm{mg} /$ day and increased to $54 \mathrm{mg} /$ day. ADHD symptoms decreased after 2 weeks and craving for cocaine disappeared after 1 month of treatment. The patient stayed abstinent from cocaine and alcohol and quit gambling and compulsive sex, as shown in a 1-year follow-up. The other report ${ }^{110}$ depicts the case of a cocaine- and alcohol-dependent borderline illiterate man with difficulties in attention, restlessness, and hyperactivity during childhood. Treatment was started with SR MPH $36 \mathrm{mg} /$ day and reduced to $27 \mathrm{mg} /$ day. The patient described the treatment as "a miracle" since he 
Table I Overview of case reports and clinical trials addressing methylphenidate as a treatment for cocaine dependence

\begin{tabular}{|c|c|c|c|c|}
\hline $\begin{array}{l}\text { Author } \\
\text { (year) }\end{array}$ & Participants & Intervention & Outcome measures & Findings \\
\hline \multicolumn{5}{|l|}{ Case reports } \\
\hline $\begin{array}{l}\text { Khantzian } \\
(1983)^{23}\end{array}$ & $\begin{array}{l}\text { One female outpatient } \\
\text { with childhood history } \\
\text { indicative of ADHD }\end{array}$ & MPH starting dose $15 \mathrm{mg}$ tid & Urinalysis, self-reports & $\begin{array}{l}\text { MPH effective in reducing cocaine } \\
\text { use }\end{array}$ \\
\hline $\begin{array}{l}\text { Khantzian } \\
\text { et al }(1984)^{108}\end{array}$ & $\begin{array}{l}\text { Three patients (one } \\
\text { female, two male), } \\
\text { one male with ADHD }\end{array}$ & $\begin{array}{l}\text { MPH starting dose } 15 \mathrm{mg} \text { tid or } \\
5 \mathrm{mg} \text { qid, } \mathrm{max} 70 \mathrm{mg} / \text { day }\end{array}$ & Urinalysis, self-reports & $\begin{array}{l}\text { MPH effective in reducing cocaine } \\
\text { use }\end{array}$ \\
\hline $\begin{array}{l}\text { Imbert } \\
\text { et al }(2014)^{109}\end{array}$ & $\begin{array}{l}\text { One male outpatient } \\
\text { with adult ADHD }\end{array}$ & $\begin{array}{l}\text { SR MPH starting dose } 18 \mathrm{mg} / \text { day, } \\
\text { increased to } 54 \mathrm{mg} / \text { day }\end{array}$ & $\begin{array}{l}\text { Urinalysis, clinical } \\
\text { examination, CCQ-Brief }\end{array}$ & $\begin{array}{l}\text { MPH effective in reducing cocaine } \\
\text { use }\end{array}$ \\
\hline $\begin{array}{l}\text { Mariani } \\
\text { et al }(20 \mid 4)^{110}\end{array}$ & One male outpatient & $\begin{array}{l}\text { SR MPH starting dose } 36 \mathrm{mg} / \mathrm{day} \text {, } \\
\text { decreased to } 27 \mathrm{mg} / \mathrm{day}\end{array}$ & $\begin{array}{l}\text { Urinalysis, self-reported } \\
\text { cocaine use }\end{array}$ & $\begin{array}{l}\text { MPH effective in reducing cocaine } \\
\text { use }\end{array}$ \\
\hline $\begin{array}{l}\text { Gawin } \\
\text { et al (1985)'"' }\end{array}$ & $\begin{array}{l}\text { Five male patients } \\
\text { without ADHD }\end{array}$ & $\begin{array}{l}\text { MPH starting dose } 20 \text { or } 40 \mathrm{mg} / \text { day, } \\
\max 100 \mathrm{mg} / \text { day }\end{array}$ & $\begin{array}{l}\text { Self-reported cocaine } \\
\text { craving and use }\end{array}$ & $\begin{array}{l}\text { MPH not effective, increased } \\
\text { cocaine use and craving }\end{array}$ \\
\hline \multicolumn{5}{|c|}{ Open-label trials } \\
\hline $\begin{array}{l}\text { Levin } \\
\text { et al }(1998)^{112}\end{array}$ & $\begin{array}{l}\text { I } 2 \text { outpatients with } \\
\text { adult } A D H D\end{array}$ & SR MPH doses from 20 to $40 \mathrm{mg}$ bid & $\begin{array}{l}\text { Urinalysis (tiw), ASI, side } \\
\text { effects checklist, cocaine- } \\
\text { craving questionnaire }\end{array}$ & $\begin{array}{l}\text { MPH effective in reducing cocaine } \\
\text { use; eight patients completed the } \\
\text { study }\end{array}$ \\
\hline $\begin{array}{l}\text { Castaneda } \\
\text { et al }(1999)^{113}\end{array}$ & $\begin{array}{l}19 \text { private patients } \\
\text { with adult ADHD } \\
\text { (17 males) }\end{array}$ & $\begin{array}{l}\text { Fluoxetine } 20 \mathrm{mg} \\
\text { Bupropion } 100 \mathrm{mg} \\
\text { Pemoline } 37.5 \mathrm{mg} \\
\text { SR MPH } 20 \mathrm{mg} \\
\text { Dextroamphetamine } 10 \mathrm{mg} \\
\text { Methamphetamine } 15 \mathrm{mg}\end{array}$ & Urinalysis (qw or biw) & $\begin{array}{l}\text { LA stimulants alone or in } \\
\text { combination with fluoxetine or } \\
\text { bupropion most effective }\end{array}$ \\
\hline $\begin{array}{l}\text { Somoza } \\
\text { et al }(2004)^{1 / 4}\end{array}$ & $\begin{array}{l}4 I \text { outpatients with } \\
\text { adult } A D H D\end{array}$ & $\begin{array}{l}\text { IR MPH starting dose } 20 \mathrm{mg} / \mathrm{day} \text {, } \\
\max 20 \mathrm{mg} \text { tid }\end{array}$ & $\begin{array}{l}\text { Urinalysis (tiw), CGI, } \\
\text { ASI, Substance Use } \\
\text { Questionnaire, BSCS, } \\
\text { CCQ-GEN, vital signs } \\
\text { and adverse events, } \\
\text { retention in treatment }\end{array}$ & $\begin{array}{l}\text { MPH effective in compliant } \\
\text { patients; } 70 \% \text { completed the study }\end{array}$ \\
\hline \multicolumn{5}{|c|}{ Double-blind, randomized, placebo-controlled studies } \\
\hline $\begin{array}{l}\text { Levin } \\
\text { et al }(2007)^{118}\end{array}$ & $\begin{array}{l}\text { I06 outpatients } \\
\text { with adult ADHD } \\
\text { ( } 83 \% \text { males })\end{array}$ & $\begin{array}{l}\text { I. IR MPH starting dose } 10 \mathrm{mg} / \text { day, } \\
\text { SR MPH max } 60 \mathrm{mg} / \text { day }(40 \mathrm{mg} \text { am, } \\
20 \mathrm{mg} \mathrm{Pm}) ; \mathrm{n}=53 \\
\text { 2. Placebo; } \mathrm{n}=53\end{array}$ & $\begin{array}{l}\text { Urinalysis (tiw), } \\
\text { self-reports, retention } \\
\text { in treatment }\end{array}$ & $\begin{array}{l}\text { MPH reduced likelihood of cocaine } \\
\text { use over time; } 23 \text { patients of } \\
\text { group I and } 24 \text { patients of group } 2 \\
\text { completed the study }\end{array}$ \\
\hline $\begin{array}{l}\text { Grabowski } \\
\text { et al }(1997)^{59}\end{array}$ & $\begin{array}{l}49 \text { outpatients without } \\
\text { ADHD }\end{array}$ & $\begin{array}{l}\text { I. MPH } 45 \mathrm{mg} / \text { day ( } 5 \mathrm{mg} \text { IR and } \\
20 \mathrm{mg} \text { SR MPH am, } 20 \mathrm{mg} \text { SR pm); } \\
\mathrm{n}=25 \\
\text { 2. Placebo; } \mathrm{n}=24\end{array}$ & $\begin{array}{l}\text { Urinalysis (biw), ASI, } \\
\text { SEQ, retention } \\
\text { in treatment }\end{array}$ & $\begin{array}{l}\text { No advantage of MPH over placebo } \\
\text { in reducing cocaine use; } \\
48 \% \text { of group I and } 42 \% \text { of } \\
\text { group } 2 \text { completed the study }\end{array}$ \\
\hline $\begin{array}{l}\text { Schubiner } \\
\text { et al }(2002)^{61}\end{array}$ & $\begin{array}{l}48 \text { outpatients } \\
\text { with adult ADHD } \\
\text { ( } 43 \text { males) }\end{array}$ & $\begin{array}{l}\text { I. } M P H 30 \mathrm{mg} / \mathrm{tid} ; \mathrm{n}=24 \\
\text { 2. Placebo; } \mathrm{n}=24\end{array}$ & $\begin{array}{l}\text { Urinalysis (tiw), ASI, } \\
\text { CCQ-GEN, self-reports, } \\
\text { side effects checklist, } \\
\text { retention in treatment }\end{array}$ & $\begin{array}{l}\text { No advantage of MPH over placebo } \\
\text { in reducing cocaine use; } \\
45 \% \text { of group I and } 58 \% \text { of } \\
\text { group } 2 \text { completed the study }\end{array}$ \\
\hline $\begin{array}{l}\text { Levin et al } \\
(2006)^{117}\end{array}$ & $\begin{array}{l}98 \text { methadone- } \\
\text { maintained outpatients } \\
\text { with adult ADHD } \\
\text { ( } 57 \% \text { males })\end{array}$ & $\begin{array}{l}\text { I. IR MPH starting dose } 5 \mathrm{mg} / \mathrm{bid} \text {, } \\
\text { SR MPH max } 40 \mathrm{mg} / \mathrm{bid} ; \mathrm{n}=32 \\
\text { 2. SR bupropion } \max 400 \mathrm{mg} / \text { day; } \mathrm{n}=33 \\
\text { 3. Placebo; } \mathrm{n}=33\end{array}$ & $\begin{array}{l}\text { Urinalysis (tiw), } \\
\text { self-reports, retention } \\
\text { in treatment }\end{array}$ & $\begin{array}{l}\text { No advantage of active medications } \\
\text { over placebo in reducing cocaine use; } \\
2 \text { I patients of group I, } 23 \text { patients of } \\
\text { group } 2 \text {, and } 25 \text { patients of group } 3 \\
\text { completed the study }\end{array}$ \\
\hline $\begin{array}{l}\text { Dürsteler- } \\
\text { MacFarland } \\
\text { et al }(2013)^{31}\end{array}$ & $\begin{array}{l}62 \text { diacetylmorphine- } \\
\text { maintained outpatients } \\
\text { ( } 40 \text { males) }\end{array}$ & $\begin{array}{l}\text { I. IR MPH } 30 \mathrm{mg} \text { bid + CBGT; } \mathrm{n}=15 \\
\text { 2. IR MPH } 30 \mathrm{mg} \text { bid + treatment } \\
\text { as usual; } \mathrm{n}=15 \\
\text { 3. Placebo + CBGT; } \mathrm{n}=17 \\
\text { 4. Placebo + treatment as usual; } \mathrm{n}=15\end{array}$ & $\begin{array}{l}\text { Urinalysis (tiw), } \\
\text { self-reports, adverse } \\
\text { effects, retention } \\
\text { in treatment }\end{array}$ & $\begin{array}{l}\text { No advantage of } \mathrm{MPH} \text { over } \\
\text { placebo in reducing cocaine use, no } \\
\text { additive effects of MPH and CBT; } \\
71 \% \text { completed the study with no } \\
\text { between-group differences }\end{array}$ \\
\hline
\end{tabular}

Note: \#Medications were introduced in an order inversely related to their expected degree of stimulant effects and were replaced when the medication did not substantially improve ADHD symptoms after 2 weeks or after having doubled the dose.

Abbreviations: ADHD, attention deficit hyperactivity disorder; ASI, Addiction Severity Index; bid, two times per day; biw, two times per week; BSCS, Brief Substance Craving Scale; CBGT, cognitive-behavioral group therapy; CBT, cognitive-behavioral therapy; CCQ-Brief, Cocaine Craving Questionnaire-Brief; CCQ-GEN, Cocaine Craving Questionnaire-General; CGI, Clinical Global Impression Scale; IR, immediate-release; LA, long-acting; MPH, methylphenidate; qid, four times per day; qw, once per week; SEQ, Side Effects Questionnaire; SR, sustained-release; tid, three times per day; tiw, three times per week. 
felt much better after only 1 day of medication. Apart from one minor slip, the patient had stayed abstinent from cocaine for 8 months at the time of writing the report.

In another series of case reports, ${ }^{111}$ five male cocaine users without $\mathrm{ADHD}$ received MPH to treat cocaine dependence. MPH was started at doses of 20 or $40 \mathrm{mg} /$ day, which were individually increased up to $100 \mathrm{mg} /$ day. MPH treatment lasted between 2 and 5 weeks before it was discontinued in all patients due to increased cocaine craving and use. Initially, most patients experienced a short duration of positive medication effects, but they rapidly built up tolerance to $\mathrm{MPH}$. Furthermore, patients stated that MPH lacked the desired "rush", which might also have led to the increased cocaine craving and use. The authors concluded that treatment with MPH is not successful in cocaine-dependent patients without comorbid ADHD.

\section{Open-label studies}

The first open-label study that investigated the effectiveness of MPH as treatment for both cocaine use and ADHD included 12 cocaine-dependent outpatients with adult ADHD. ${ }^{112}$ Doses from 40 to $80 \mathrm{mg}$ /day were used in this 12-week study, in which ten participants remained for at least 8 weeks, while eight of them completed the study. The most common side effects reported were dry mouth, increased heart rate, agitation, and jitteriness. No participant discontinued the study due to side effects. Participants showed significant improvement in all ADHD symptoms (except mood lability) of almost $50 \%$ on psychometric measures. Cocaine craving and use had decreased significantly when the first 2 study weeks were compared to the last 2 weeks. Seven of the eight study completers were reachable for a follow-up 3 months later: three who still received MPH were cocaine-abstinent, as were two who were no longer treated with $\mathrm{MPH}$, while two provided cocaine-positive urine samples.

Castaneda et $\mathrm{al}^{113}$ addressed a subgroup of cocainedependent patients who reported how cocaine had had a paradoxically calming effect on them at the beginning of their cocaine use. All these patients were diagnosed as having adult ADHD, which led the authors to conclude that these cocainedependent patients might have self-medicated their ADHD symptoms with cocaine, for which they report additional evidence in their study. Nineteen outpatients with adult ADHD and cocaine dependence in full remission were enrolled to this year-long, open-label, prospective study, which aimed at minimizing the risk of medication abuse or cocaine relapse. Before treatment for ADHD could be started, patients had to be abstinent from cocaine for 6 months or longer. Several medications were introduced for ADHD treatment in an order inversely related to their expected degree of stimulant effects and were replaced when the medication did not substantially improve ADHD symptoms after 2 weeks or after having doubled the dose. Treatment was viewed as fully effective when it decreased initial ADHD symptoms for a minimum of 12 months. Medications were administered in the following order and starting doses: fluoxetine $20 \mathrm{mg}$, bupropion $100 \mathrm{mg}$, pemoline $37.5 \mathrm{mg}$, SR MPH $20 \mathrm{mg}$, dextroamphetamine $10 \mathrm{mg}$, and methamphetamine $15 \mathrm{mg}$. Therapy with a longacting stimulant (mostly SR MPH) alone or combined with fluoxetine or bupropion was most effective in suppressing ADHD symptoms. Fully effective treatment responses were achieved in 18 out of the 19 participants. The applied treatment strategy was found to be highly effective for treating ADHD symptoms, with cocaine use occurring only in four out of the 19 patients (two slips, two relapses).

Somoza et $\mathrm{al}^{114}$ also hypothesized that MPH could be safely and effectively used for the treatment of individuals with comorbid ADHD and cocaine dependence (mostly crack use). IR MPH was started at $20 \mathrm{mg}$ /day and increased to a dose of $20 \mathrm{mg}$ tid. Of the 41 outpatients enrolled in this 10-week, open-label study, 19 were rated as being compliant due to MPH plasma levels and ratings of the staff. Seventy percent of the participants completed the study. A significant difference in study retention was found between compliant and noncompliant participants. MPH was concluded to be safe with a minimum of side effects which were not serious and did not persist on a moderate or severe rating. With respect to cocaine use, study results showed that only participants reported to be compliant benefited from MPH. Compared to $0 \%$ of the noncompliant participants, $37 \%$ of the compliant stayed abstinent from cocaine during the study. A comparison of baseline and endpoint ADHD measures, however, revealed that ADHD symptoms had improved significantly in all participants, irrespective of compliance.

\section{Randomized controlled trials}

Five double-blind, randomized, and placebo-controlled trials on the efficacy of MPH as replacement therapy for cocaine dependence have been published so far. One other randomized but single-blind trial ${ }^{115}$ was excluded from this review as its main focus does not lie on the management of cocaine dependence. Grabowski et al ${ }^{59}$ were the first to investigate this treatment approach in 49 cocaine-dependent outpatients with no other major mental health disorders who 
were randomized to receive either MPH or a placebo. After a 2-week intake period, a dosage of MPH $45 \mathrm{mg}$ /day was administered during the 11-week treatment phase. There was no between-group difference in study retention, with 24 participants completing the trial. Study results showed no adverse effects of MPH and no increase of cocaine use. However, there was also no significant difference in cocaine use between the study groups; both groups continued to use cocaine. With respect to self-report items (eight items from Side Effects Questionnaire assessing direct drug effects) the two groups differed in the items "eating less", "drowsy", and "more energy", suggesting that the MPH but not the placebo group noticed a direct effect of medication.

Dürsteler-MacFarland et $\mathrm{al}^{31}$ evaluated the feasibility, tolerability, and efficacy of MPH and cognitive-behavioral group therapy (CBGT) for cocaine dependence in patients prescribed diacetylmorphine. Sixty-two cocaine-dependent, diacetylmorphine-maintained patients participated in this dual-site, double-blind, placebo-controlled trial with four treatment arms. They were randomly assigned to receive MPH or placebo, each of which combined with either CBGT or treatment as usual for 12 weeks. After a baseline week, IR MPH $30 \mathrm{mg}$ two times per day (bid) and placebo in identical capsules were administered under supervision. Manual-guided CBGT consisted of 12 weekly sessions in groups of five to seven patients. Primary outcome measures were cocaine-free urine samples, retention in pharmacologic treatment, and adverse effects. Urine cocaine screens were performed thrice weekly. Seventy-one percent of participants completed the trial. MPH was well tolerated with similar retention rates compared to placebo. No serious MPH-related adverse effects occurred. However, without reaching statistical significance, participants receiving MPH reported more side effects than those receiving placebo; these occurred at the beginning of the trial and disappeared soon after. The most common reported side effects were insomnia, dry mouth, hyperactivity, loss of appetite, and cardiac palpitations. There was a significant decline in self-reported amount and frequency of cocaine use in all groups, but data showed no significant change in cocaine-free urine samples. MPH did not provide an advantage over placebo in reducing cocaine use. In contrast to positive results obtained in other samples, this study does not support a role for CBGT for treating cocaine dependence in this patient group. There were no signs of additive benefits of MPH and CBGT.

ADHD is a common psychiatric comorbidity among cocaine-dependent individuals, with prevalence rates of up to $30 \%$ in some studies. ${ }^{116}$ Based on the self-medication hypothesis, ${ }^{23}$ other controlled trials have therefore evaluated the efficacy of MPH treatment for adult ADHD and comorbid cocaine dependence. The assumption hereby is that MPH might have a beneficial effect on ADHD symptoms which would also lead to a decline in cocaine use. Schubiner et al ${ }^{61}$ addressed this hypothesis in 48 cocaine-dependent patients with adult ADHD in a 12-week double-blind, placebo-controlled trial after a baseline week. MPH doses were titrated from an initial dosage for the first 2 or 3 days ( $10 \mathrm{mg}$ tid) to a second dosage level (20 mg tid) for the next 4 to 5 days to the target dose of MPH $30 \mathrm{mg}$ tid by day 8 . Retention in the study did not differ by group; $45 \%$ of the MPH and $58 \%$ of the placebo group completed the study. However, participants from the placebo group were less likely to drop out before the end of study week 4 than those from the MPH group. Reported side effects were generally high before the medication phase and remained so throughout the trial. Intensity of insomnia and sadness in the MPH group were higher at baseline and during the study than in the placebo group. A dose reduction was required in $25 \%$ of the participants receiving MPH; however, none of them discontinued the trial due to adverse side effects. The study demonstrated the safety of supratherapeutic doses of MPH in cocaine-dependent patients with adult ADHD. Although MPH did not decrease cocaine use or craving, it improved subjective reports of ADHD symptoms as compared to placebo.

Levin et $\mathrm{al}^{117}$ compared the efficacy of SR MPH or SR bupropion to placebo in treating ADHD symptoms and additional cocaine use. The sample included 98 methadonemaintained patients with adult ADHD, of whom 53\% also met criteria for cocaine abuse or dependence. Participants were randomly assigned to the $\mathrm{MPH}$, bupropion, or placebo treatment. The 12-week study duration included a 2-week lead-in phase with placebo, a 2-week titration phase, and 8 weeks at stable doses. MPH was started at $5 \mathrm{mg}$ bid with standard formula and increased to a maximum dose of SR MPH $40 \mathrm{mg}$ bid. Bupropion was started at $100 \mathrm{mg} /$ day and increased to a maximum dose of $200 \mathrm{mg}$ bid. Overall, 69 participants completed the study; the groups did not differ in retention rates. The results showed a reduction of ADHD symptoms in all three study groups. However, there were no significant group differences, suggesting that neither SR MPH nor SR BPR is more effective than placebo in treating ADHD symptoms in these patients. In terms of cocaine use, subgroup analysis demonstrated a high proportion of cocainepositive weeks across all groups throughout the trial, whereby active medication had no advantage over placebo in improving cocaine use. Nevertheless, no evidence of medication abuse was found and both medications were well tolerated 
with no adverse side effects. The most common side effects were fatigue and increased sweating. No group differences were observed with respect to side effects.

Another double-blind trial by Levin et $\mathrm{al}^{118}$ hypothesized that treatment with MPH would lead to greater improvement of ADHD symptoms and cocaine use than placebo. The sample consisted of 106 adult ADHD outpatients with comorbid cocaine dependence who participated in this 14-week trial (1 week placebo lead in, 2-week titration phase, and 11 weeks of medication treatment). MPH was started at $10 \mathrm{mg}$ /day standard formulation and increased to a maximum dose of $60 \mathrm{mg}$ /day of SR MPH (40 mg in the morning and $20 \mathrm{mg}$ in the afternoon). Retention in treatment did not differ between groups. Eighty-nine participants, of whom 47 completed the trial, remained at least 4 weeks in the study. A variety of side effects were reported across both groups but there were no significant group differences. The most frequently reported side effects were headache, gastrointestinal upset, diarrhea, and insomnia. Most of the participants reported at least a $30 \%$ decrease in ADHD symptoms. However, in contrast to Schubiner et al, ${ }^{61}$ this study did not find a significant difference between the groups. Although there was no substantial improvement in cocaine abstinence in either group, those receiving $\mathrm{MPH}$ had a reduced likelihood of cocaine use over time. A secondary analysis showed no improvement in cocaine use for participants in the placebo group, regardless of ADHD response. However, in the MPH group, the likelihood of submitting cocaine-positive urine samples decreased by $36 \%$ over time for ADHD responders compared to under $10 \%$ for ADHD nonresponders, suggesting a beneficial effect of MPH treatment in this group.

To summarize, all double-blind, placebo-controlled trials confirmed that the administration of up to MPH $90 \mathrm{mg}$ /day to cocaine-dependent patients with or without adult ADHD and/or with simultaneous diacetylmorphine or methadone maintenance is safe and does not increase cocaine use or craving. However, in contrast to most open-label studies, the more rigorously controlled studies were not able to show a substantial decrease of cocaine use through MPH treatment.

\section{Discussion}

Overall, the findings from human laboratory and clinical studies assessing the clinical potential of MPH as an agonist medication for cocaine dependence are inconclusive. Controlled laboratory studies have shown that MPH can be safely administered in combination with cocaine without relevant clinical consequences and that MPH substitution reduces some of the positive effects of cocaine. ${ }^{58,60,107}$ With one exception, ${ }^{111}$ the available case reports ${ }^{23,43,108,109}$ and openlabel studies ${ }^{112-114}$ also suggest that substitution with MPH might be a safe and effective treatment intervention in cocaine dependence, especially in those with comorbid ADHD. In contrast, randomized controlled trials do not provide evidence for the effectiveness of MPH as replacement therapy, at least in those patients who do not additionally suffer from ADHD; yet, they have demonstrated that MPH is well tolerated and remarkably safe with minimal side effects in active cocaine users. ${ }^{31,59,61,117,118}$ However, there are several explanations for the negative results of these trials which should be considered when discussing the potential of MPH as a substitution therapy for cocaine dependence and planning further studies. The negative findings may in part be due to relatively small sample sizes, the dose and formulation of MPH used, the duration of MPH treatment and time point of its initiation, as well as patient characteristics.

A general problem of randomized controlled trials is that there are upper limits of dosing. These limits may not adequately approximate the cocaine use patterns in naturalistic settings. The MPH doses administered in the trials so far might be too small to be effective. In fact, laboratory data indicate that higher doses of MPH more effectively attenuate cocaine's positive subjective effects and decrease choices for cocaine over money in cocaine users. ${ }^{58,60}$ Some evidence also suggests that chronic cocaine use decreases sensitivity to dopaminergic medications. ${ }^{49}$ This means that dosing at the high end of the recommended range or above would be required to be effective in cocaine dependence. These doses, however, might be much higher than those commonly used for the treatment of ADHD and may increase the risk for side effects and especially for severe adverse events. ${ }^{61,119}$ Even at dosages of $90 \mathrm{mg}$ /day, MPH did not show advantage over placebo in terms of cocaine use. ${ }^{61}$ Hence, $\mathrm{MPH}$ in therapeutic doses may be best suited for low-to-moderate severity of cocaine dependence. Connected to the cocaine users' decreased sensitivity to dopaminergic medications, the duration of treatment and the time point of treatment initiation may also be critical determinants for effectiveness. Time to maximal reduction in cocaine use can vary considerably and may take several months. Such a delay between treatment initiation with MPH and reduction in drug use has been reported for amphetamine-dependent participants receiving a terminal dose of $54 \mathrm{mg}$ /day of extended-release $\mathrm{MPH} .{ }^{120}$ In that study, 18 weeks of MPH treatment were required to significantly reduce amphetamine use. Furthermore, treatment with MPH in randomized controlled studies was induced while partici- 
pants were using cocaine. A different approach would be to start MPH treatment after participants have achieved an initial period of abstinence from cocaine (eg, via CM intervention) and to assess time to relapse and relapse rates over a longer period of time.

A recent brain imaging study has found that deficient dopamine transmission in cocaine users is associated with failure to respond to behavioral treatment. ${ }^{121}$ If deficient dopamine transmission predicts poor response to behavioral interventions, then MPH replacement therapy could potentially reverse this deficit. ${ }^{43}$ In fact, brain imaging data suggest that MPH may ameliorate various neural dysfunctions in mesocorticolimbic regions and improve neurocognitive deficits found in cocaine users. ${ }^{64,65,122-126}$ In one study, for example, a single oral dose of $20 \mathrm{mg}$ MPH normalized hypoactivation in the anterior cingulate cortex and improved behavioral measures of response inhibition. ${ }^{123}$ Moreover, Li et $\mathrm{l}^{65}$ have shown that MPH in cocaine-dependent individuals is associated with robustly decreased reaction time in the stop signal task, suggesting improvements in inhibitory control. Cognitive improvements were thereby positively correlated with inhibition-related activation in the medial frontal cortex, an area associated with motor inhibitory control. MPH has also been found to attenuate brain reactivity of cocaine-dependent participants to cocaine-related cues in a brain imaging study. ${ }^{126}$ These findings highlight another mechanism by which MPH might be beneficial in the treatment of cocaine dependence, as intact dopamine signaling is required for responding to natural and therapeutic contingencies. ${ }^{121}$ However, the potential of MPH to increase the effects of behavioral interventions warrants further well-designed studies.

Interestingly, MPH treatment in cocaine-dependent patients with ADHD who respond positively to the medication in terms of ADHD symptoms is associated with a significantly greater increase in the number of cocaine-negative urine samples compared to those who respond poorly. ${ }^{118}$ It is well known that variability in drug pharmacokinetics and pharmacodynamics are largely influenced by an individual's genetic profile. Properly assessed genetically driven functional changes in the DAT could help determine which patients could benefit from MPH for cocaine dependence. ${ }^{51,127}$ Individuals with variable number tandem repeats of the SLC6Q3 gene 3'-untranslated region polymorphism of DAT1 have been found to have altered responses to drugs, with the $10 / 10$ repeat responding poorly to $\mathrm{MPH}$. An example of a study of a predictive genetic biomarker in cocaine dependence has recently been published, ${ }^{128}$ but there are no data available for MPH treatment in cocaine dependence.

Some randomized controlled trials ${ }^{31,117}$ described above were conducted in polysubstance users maintained on methadone or diacetylmorphine. This may have influenced the results; smaller doses of MPH may be less effective in polydrug users or effects of ongoing substance use and potential withdrawal symptoms may have interfered with the studies. However, opioid withdrawal symptoms should be minimized or absent in patients on stable opioid maintenance. Furthermore, concomitant use of other substances is highly prevalent in cocaine users, and this population should therefore be included in the research on the effectiveness of a substitution approach for cocaine addiction.

Several studies on cocaine dependence suggest a differential treatment outcome by sex. ${ }^{129}$ Moreover, the menstrual cycle and levels of gonadal hormones can influence dopamine function, subjective effects of stimulants, and responsiveness to potential treatments. ${ }^{130}$ Because, typically, cocaine dependence is more prevalent in males, female patients are less often enrolled in studies, and this is also the case for the studies described here. Correspondingly, the results may be more representative of male cocaine users. None of the studies on MPH in cocaine dependence reported sex-specific effects; however, the number of enrolled females may have been too small to conduct these analyses. Future studies should take sex-specific effects and menstrual cycle into account.

Although there is no evidence from randomized controlled trials that MPH is superior over placebo in reducing cocaine use in cocaine-dependent patients without ADHD, clinical experience suggests that MPH might be beneficial for some patients when treatment is appropriately tailored to the individual patient. ${ }^{23,43,108,109}$ Therefore, substitution therapy with MPH appears to be viable, with risks outweighed by benefits in carefully selected, monitored, and motivated patients. In these cases, SR or newer extended-release preparations of MPH are generally to be preferred over IR formulations for purposes of behavioral safety. However, further research is required to determine optimal treatment models (initiation after achieving a period of cocaine abstinence or during active cocaine use), effective and safe doses, and length of treatment. From these points of view, further well-designed studies are needed to better evaluate the clinical potential of MPH as possible treatment for cocaine dependence. Future trials should be conducted in larger samples of clinically and genetically well-characterized participants, over a longer duration and with higher doses of supervised MPH administration, best combined with $\mathrm{CM}$, 
likely the most robust behavioral intervention available for cocaine dependence followed by CBT.

\section{Disclosure}

The authors report no conflicts of interest in this work.

\section{References}

1. United Nations Office on Drugs and Crime (UNODC). World Drug Report 2013. New York: United Nations; 2013.

2. United Nations Office on Drugs and Crime (UNODC). World Drug Report 2012. New York: United Nations; 2012.

3. European Monitoring Centre for Drugs and Drug Addiction (EMCDDA). European drug report 2014: Trends and developments. Lisbon: EMCDDA; 2014. Available from: http://www.emcdda.europa.eu/publications/edr/trends-developments/2014. Accessed May 1, 2015.

4. Ort C, van Nuijs AL, Berset JD, et al. Spatial differences and temporal changes in illicit drug use in Europe quantified by wastewater analysis. Addiction. 2014;109:1338-1352.

5. Degenhardt L, Hall W. Extent of illicit drug use and dependence, and their contribution to the global burden of disease. Lancet. 2012;379:55-70.

6. European Monitoring Centre for Drugs and Drug Addiction (EMCDDA). Selected Issue 2007: Cocaine and Crack Cocaine: A Growing Public Health Issue. Luxembourg: Office for Official Publications of the European Communities; 2007.

7. Kaye S, Darke S. Injecting and non-injecting cocaine use in Sydney, Australia: physical and psychological morbidity. Drug Alcohol Rev. 2004;23:391-398.

8. Macdonald S, Anglin-Bodrug K, Mann RE, et al. Injury risk associated with cannabis and cocaine use. Drug Alcohol Depend. 2003;72: 99-115.

9. Maraj S, Figueredo VM, Lynn Morris D. Cocaine and the heart. Clin Cardiol. 2010;33:264-269.

10. Marzuk PM, Tardiff K, Leon AC, et al. Fatal injuries after cocaine use as a leading cause of death among young adults in New York City. N Engl J Med. 1995;332:1753-1757.

11. Qureshi AI, Chaudhry SA, Suri MF. Cocaine use and the likelihood of cardiovascular and all-cause mortality: data from the Third National Health and Nutrition Examination Survey Mortality Follow-up Study. J Vasc Interv Neurol. 2014;7:76-82.

12. Tardiff K, Marzuk PM, Leon AC, Portera L, Weiner C. Violence by patients admitted to a private psychiatric hospital. Am J Psychiatry. 1997; 154:88-93

13. Barrio G, Molist G, de la Fuente L, et al; Itinere Working Group. Mortality in a cohort of young primary cocaine users: controlling the effect of the riskiest drug-use behaviors. Addict Behav. 2013;38:1601-1604.

14. Wagner FA, Anthony JC. From first drug use to drug dependence; developmental periods of risk for dependence upon marijuana, cocaine, and alcohol. Neuropsychopharmacology. 2002;26:479-488.

15. Degenhardt L, Baxter AJ, Lee YY, et al. The global epidemiology and burden of psychostimulant dependence: findings from the Global Burden of Disease Study 2010. Drug Alcohol Depend. 2014;137:36-47.

16. van de Glind G, Konstenius M, Koeter MW, et al; IASP Research Group. Variability in the prevalence of adult ADHD in treatment seeking substance use disorder patients: results from an international multi-center study exploring DSM-IV and DSM-5 criteria. Drug Alcohol Depend. 2014;134:158-166.

17. Wilens TE, Biederman J, Spencer TJ, Frances RJ. Comorbidity of attention-deficit hyperactivity and psychoactive substance use disorders. Hosp Community Psychiatry. 1994;45:421-423, 435.

18. Chronis AM, Lahey BB, Pelham WE Jr, Kipp HL, Baumann BL, Lee SS. Psychopathology and substance abuse in parents of young children with attention-deficit/hyperactivity disorder. J Am Acad Child Adolesc Psychiatry. 2003;42:1424-1432.
19. Schuckit MA, Smith TL. An 8-year follow-up of 450 sons of alcoholic and control subjects. Arch Gen Psychiatry. 1996;53:202-210.

20. Cunha PJ, Gonçalves PD, Ometto M, et al. Executive cognitive dysfunction and ADHD in cocaine dependence: searching for a common cognitive endophenotype for addictive disorders. Front Psychiatry. 2013;4:126.

21. Volkow ND, Wang GJ, Kollins SH, et al. Evaluating dopamine reward pathway in ADHD: clinical implications. JAMA. 2009;302: 1084-1091.

22. Young SE, Friedman NP, Miyake A, et al. Behavioral disinhibition: liability for externalizing spectrum disorders and its genetic and environmental relation to response inhibition across adolescence. J Abnorm Psychol. 2009;118:117-130.

23. Khantzian EJ. An extreme case of cocaine dependence and marked improvement with methylphenidate treatment. Am J Psychiatry. 1983;140:784-785.

24. Prendergast M, Podus D, Finney J, Greenwell L, Roll J. Contingency management for treatment of substance use disorders: a meta-analysis Addiction. 2006;101:1546-1560.

25. Weiss LM, Petry NM. Substance abuse treatment patients with early onset cocaine use respond as well to contingency management interventions as those with later onset cocaine use. $J$ Subst Abuse Treat. 2014:47:146-150.

26. Epstein DH, Hawkins WE, Covi L, Umbricht A, Preston KL. Cognitive-behavioral therapy plus contingency management for cocaine use: findings during treatment and across 12-month follow-up. Psychol Addict Behav. 2003;17:73-82.

27. Carroll KM, Onken LS. Behavioral therapies for drug abuse. Am J Psychiatry. 2005;162:1452-1460.

28. Dutra L, Stathopoulou G, Basden SL, Leyro TM, Powers MB, Otto MW. A meta-analytic review of psychosocial interventions for substance use disorders. Am J Psychiatry. 2008;165:179-187.

29. Brensilver M, Heinzerling KG, Shoptaw S. Pharmacotherapy of amphetamine-type stimulant dependence: an update. Drug Alcohol Rev. 2013;32:449-460.

30. Aharonovich E, Hasin DS, Brooks AC, Liu X, Bisaga A, Nunes EV. Cognitive deficits predict low treatment retention in cocaine dependent patients. Drug Alcohol Depend. 2006;81:313-322.

31. Dürsteler-MacFarland KM, Farronato NS, Strasser J, et al. A randomized, controlled, pilot trial of methylphenidate and cognitive-behavioral group therapy for cocaine dependence in heroin prescription. $J$ Clin Psychopharmacol. 2013;33:104-108.

32. Aharonovich E, Amrhein PC, Bisaga A, Nunes EV, Hasin DS. Cognition, commitment language, and behavioral change among cocaine-dependent patients. Psychol Addict Behav. 2008;22:557-562.

33. Carroll KM, Nich C, Ball SA. Practice makes progress? Homework assignments and outcome in treatment of cocaine dependence. J Consult Clin Psychol. 2005;73:749-755.

34. Gonzalez VM, Schmitz JM, DeLaune KA. The role of homework in cognitive-behavioral therapy for cocaine dependence. J Consult Clin Psychol. 2006;74:633-637.

35. Carroll KM, Fenton LR, Ball SA, et al. Efficacy of disulfiram and cognitive behavior therapy in cocaine-dependent outpatients: a randomized placebo-controlled trial. Arch Gen Psychiatry. 2004;61:264-272.

36. Vocci FJ, Montoya ID. Psychological treatments for stimulant misuse, comparing and contrasting those for amphetamine dependence and those for cocaine dependence. Curr Opin Psychiatry. 2009;22:263-268.

37. Amato L, Davoli M, Perucci CA, Ferri M, Faggiano F, Mattick RP. An overview of systematic reviews of the effectiveness of opiate maintenance therapies: available evidence to inform clinical practice and research. J Subst Abuse Treat. 2005;28:321-329.

38. Kreek MJ, Vocci FJ. History and current status of opioid maintenance treatments: blending conference session. J Subst Abuse Treat. 2002;23: 93-105.

39. Aubin HJ, Luquiens A, Berlin I. Pharmacotherapy for smoking cessation: pharmacological principles and clinical practice. $\mathrm{Br} J$ Clin Pharmacol. 2014;77:324-336. 
40. Berrettini WH, Lerman CE. Pharmacotherapy and pharmacogenetics of nicotine dependence. Am J Psychiatry. 2005;162:1441-1451.

41. Gorelick DA, Gardner EL, Xi ZX. Agents in development for the management of cocaine abuse. Drugs. 2004;64:1547-1573.

42. Rush CR, Stoops WW. Agonist replacement therapy for cocaine dependence: a translational review. Future Med Chem. 2012;4:245-265.

43. Mariani JJ, Levin FR. Psychostimulant treatment of cocaine dependence. Psychiatr Clin North Am. 2012;35:425-439.

44. Stoops WW, Rush CR. Agonist replacement for stimulant dependence: a review of clinical research. Curr Pharm Des. 2013;19:7026-7035.

45. Ritz MC, Lamb RJ, Goldberg SR, Kuhar MJ. Cocaine receptors on dopamine transporters are related to self-administration of cocaine. Science. 1987;237:1219-1223.

46. Di Chiara G, Imperato A. Drugs abused by humans preferentially increase synaptic dopamine concentrations in the mesolimbic system of freely moving rats. Proc Natl Acad Sci U S A. 1988;85:5274-5278.

47. Kuhar MJ, Ritz MC, Boja JW. The dopamine hypothesis of the reinforcing properties of cocaine. Trends Neurosci. 1991;14:299-302.

48. Calipari ES, Ferris MJ, Melchior JR, et al. Methylphenidate and cocaine self-administration produce distinct dopamine terminal alterations. Addict Biol. 2014;19:145-155.

49. Martinez D, Narendran R, Foltin RW, et al. Amphetamine-induced dopamine release: markedly blunted in cocaine dependence and predictive of the choice to self-administer cocaine. Am J Psychiatry. 2007; 164:622-629.

50. McIntosh S, Howell L, Hemby SE. Dopaminergic dysregulation in prefrontal cortex of rhesus monkeys following cocaine self-administration. Front Psychiatry. 2013;4:88.

51. Haile CN, Kosten TR. Pharmacotherapy for stimulant-related disorders. Curr Psychiatry Rep. 2013;15:415.

52. Weinshenker D, Schroeder JP. There and back again: a tale of norepinephrine and drug addiction. Neuropsychopharmacology. 2007;32:1433-1451.

53. Kalivas PW, Volkow ND. New medications for drug addiction hiding in glutamatergic neuroplasticity. Mol Psychiatry. 2011;16:974-986.

54. Rocha BA. Stimulant and reinforcing effects of cocaine in monoamine transporter knockout mice. Eur J Pharmacol. 2003;479:107-115.

55. Morton WA, Stockton GG. Methylphenidate abuse and psychiatric side effects. Prim Care Companion J Clin Psychiatry. 2000;2:159-164.

56. Leonard BE, McCartan D, White J, King DJ. Methylphenidate: a review of its neuropharmacological, neuropsychological and adverse clinical effects. Hum Psychopharmacol. 2004;19:151-180.

57. Epstein T, Patsopoulos NA, Weiser M. Immediate-release methylphenidate for attention deficit hyperactivity disorder (ADHD) in adults. Cochrane Database Syst Rev. 2014;9:CD005041.

58. Collins SL, Levin FR, Foltin RW, Kleber HD, Evans SM. Response to cocaine, alone and in combination with methylphenidate, in cocaine abusers with ADHD. Drug Alcohol Depend. 2006;82:158-167.

59. Grabowski J, Roache JD, Schmitz JM, Rhoades H, Creson D, Korszun A. Replacement medication for cocaine dependence: methylphenidate. J Clin Psychopharmacol. 1997;17:485-488.

60. Winhusen T, Somoza E, Singal BM, et al. Methylphenidate and cocaine: a placebo-controlled drug interaction study. Pharmacol Biochem Behav. 2006;85:29-38.

61. Schubiner H, Saules KK, Arfken CL, et al. Double-blind placebocontrolled trial of methylphenidate in the treatment of adult ADHD patients with comorbid cocaine dependence. Exp Clin Psychopharmacol. 2002;10:286-294.

62. Mehta MA, Owen AM, Sahakian BJ, Mavaddat N, Pickard JD, Robbins TW. Methylphenidate enhances working memory by modulating discrete frontal and parietal lobe regions in the human brain. J Neurosci. 2000;20:RC65.

63. Moeller SJ, Honorio J, Tomasi D, et al. Methylphenidate enhances executive function and optimizes prefrontal function in both health and cocaine addiction. Cereb Cortex. 2014;24:643-653.

64. Carmack SA, Block CL, Howell KK, Anagnostaras SG. Methylphenidate enhances acquisition and retention of spatial memory. Neurosci Lett. 2014;567:45-50.
65. Li CS, Morgan PT, Matuskey D, et al. Biological markers of the effects of intravenous methylphenidate on improving inhibitory control in cocaine-dependent patients. Proc Natl Acad Sci U S A. 2010;107: 14455-14459.

66. Sofuoglu M, DeVito EE, Waters AJ, Carroll KM. Cognitive enhancement as a treatment for drug addictions. Neuropharmacology. 2013;64: 452-463.

67. Angarita GA, Canavan SV, Forselius E, Bessette A, Pittman B, Morgan PT. Abstinence-related changes in sleep during treatment for cocaine dependence. Drug Alcohol Depend. 2014;134:343-347.

68. Kollins SH, MacDonald EK, Rush CR. Assessing the abuse potential of methylphenidate in nonhuman and human subjects: a review. Pharmacol Biochem Behav. 2001;68:611-627.

69. Parran TV Jr, Jasinski DR. Intravenous methylphenidate abuse. Prototype for prescription drug abuse. Arch Intern Med. 1991;151:781-783.

70. Stoops WW, Glaser PE, Fillmore MT, Rush CR. Reinforcing, subjectrated, performance and physiological effects of methylphenidate and d-amphetamine in stimulant abusing humans. $J$ Psychopharmacol. 2004; 18:534-543.

71. Kollins SH, Rush CR, Pazzaglia PJ, Ali JA. Comparison of acute behavioral effects of sustained-release and immediate-release methylphenidate. Exp Clin Psychopharmacol. 1998;6:367-374.

72. Kollins SH. Comparing the abuse potential of methylphenidate versus other stimulants: a review of available evidence and relevance to the ADHD patient. J Clin Psychiatry. 2003;64 Suppl 11:14-18.

73. Sembower MA, Ertischek MD, Buchholtz C, Dasgupta N, Schnoll SH. Surveillance of diversion and nonmedical use of extended-release prescription amphetamine and oral methylphenidate in the United States. J Addict Dis. 2013;32:26-38.

74. Kollins SH. Abuse liability of medications used to treat attention-deficit/ hyperactivity disorder (ADHD). Am J Addict. 2007;16 Suppl 1:35-42; quiz 43-34.

75. Maier LJ, Liechti ME, Herzig F, Schaub MP. To dope or not to dope: neuroenhancement with prescription drugs and drugs of abuse among Swiss university students. PLoS One. 2013;8:e77967.

76. Ritz MC, Kuhar MJ. Relationship between self-administration of amphetamine and monoamine receptors in brain: comparison with cocaine. J Pharmacol Exp Ther. 1989;248:1010-1017.

77. Fleckenstein AE, Volz TJ, Riddle EL, Gibb JW, Hanson GR. New insights into the mechanism of action of amphetamines. Annu Rev Pharmacol Toxicol. 2007;47:681-698.

78. Rothman RB, Baumann MH, Dersch CM, et al. Amphetamine-type central nervous system stimulants release norepinephrine more potently than they release dopamine and serotonin. Synapse. 2001;39:32-41.

79. Schmitt KC, Rothman RB, Reith ME. Nonclassical pharmacology of the dopamine transporter: atypical inhibitors, allosteric modulators, and partial substrates. J Pharmacol Exp Ther. 2013;346:2-10.

80. Challman TD, Lipsky JJ. Methylphenidate: its pharmacology and uses. Mayo Clin Proc. 2000;75:711-721.

81. Gatley SJ, Pan D, Chen R, Chaturvedi G, Ding YS. Affinities of methylphenidate derivatives for dopamine, norepinephrine and serotonin transporters. Life Sci. 1996;58:231-239.

82. Bymaster FP, Katner JS, Nelson DL, et al. Atomoxetine increases extracellular levels of norepinephrine and dopamine in prefrontal cortex of rat: a potential mechanism for efficacy in attention deficit/hyperactivity disorder. Neuropsychopharmacology. 2002;27:699-711.

83. Heal DJ, Gosden J, Smith SL. Dopamine reuptake transporter (DAT) "inverse agonism" - a novel hypothesis to explain the enigmatic pharmacology of cocaine. Neuropharmacology. 2014;87:19-40.

84. Volkow ND, Fowler JS, Gatley SJ, et al. Comparable changes in synaptic dopamine induced by methylphenidate and by cocaine in the baboon brain. Synapse. 1999;31:59-66.

85. Volkow ND, Fowler JS, Wang GJ. Imaging studies on the role of dopamine in cocaine reinforcement and addiction in humans. J Psychopharmacol. 1999;13:337-345.

86. Volkow ND, Swanson JM. Variables that affect the clinical use and abuse of methylphenidate in the treatment of ADHD. Am J Psychiatry. 2003;160:1909-1918. 
87. Volkow ND, Wang GJ, Fowler JS, et al. Methylphenidate and cocaine have a similar in vivo potency to block dopamine transporters in the human brain. Life Sci. 1999;65:PL7-PL12.

88. Volkow ND, Ding YS, Fowler JS, et al. Is methylphenidate like cocaine? Studies on their pharmacokinetics and distribution in the human brain. Arch Gen Psychiatry. 1995;52:456-463.

89. Volkow ND, Fowler JS, Wang GJ, Ding YS, Gatley SJ. Role of dopamine in the therapeutic and reinforcing effects of methylphenidate in humans: results from imaging studies. Eur Neuropsychopharmacol 2002; 12:557-566.

90. Volkow ND, Wang GJ, Fowler JS, et al. Relationship between psychostimulant-induced "high" and dopamine transporter occupancy. Proc Natl Acad Sci U S A. 1996;93:10388-10392.

91. Balster RL, Schuster CR. Fixed-interval schedule of cocaine reinforcement: effect of dose and infusion duration. J Exp Anal Behav. 1973;20: 119-129.

92. Volkow ND, Wang GJ, Fowler JS, et al. Blockade of striatal dopamine transporters by intravenous methylphenidate is not sufficient to induce self-reports of "high". J Pharmacol Exp Ther. 1999;288:14-20.

93. Volkow ND, Wang G, Fowler JS, et al. Therapeutic doses of oral methylphenidate significantly increase extracellular dopamine in the human brain. J Neurosci. 2001;21:RC121.

94. Volkow ND, Wang GJ, Fowler JS, et al. Dopamine transporter occupancies in the human brain induced by therapeutic doses of ora methylphenidate. Am J Psychiatry. 1998;155:1325-1331.

95. Marusich JA, Beckmann JS, Gipson CD, Bardo MT. Methylphenidate as a reinforcer for rats: contingent delivery and intake escalation. Exp Clin Psychopharmacol. 2010;18:257-266.

96. Bergman J, Madras BK, Johnson SE, Spealman RD. Effects of cocaine and related drugs in nonhuman primates. III Self-administration by squirrel monkeys. J Pharmacol Exp Ther. 1989;251:150-155.

97. Li SM, Campbell BL, Katz JL. Interactions of cocaine with dopamine uptake inhibitors or dopamine releasers in rats discriminating cocaine. J Pharmacol Exp Ther. 2006;317:1088-1096.

98. Thanos PK, Michaelides M, Benveniste H, Wang GJ, Volkow ND. Effects of chronic oral methylphenidate on cocaine self-administration and striatal dopamine D2 receptors in rodents. Pharmacol Biochem Behav. 2007;87:426-433.

99. Chait LD. Reinforcing and subjective effects of methylphenidate in humans. Behav Pharmacol. 1994;5:281-288.

100. Kollins SH, English J, Robinson R, Hallyburton M, Chrisman AK. Reinforcing and subjective effects of methylphenidate in adults with and without attention deficit hyperactivity disorder (ADHD). Psychopharmacology (Berl). 2009;204:73-83.

101. Rush CR, Kollins SH, Pazzaglia PJ. Discriminative-stimulus and participant-rated effects of methylphenidate, bupropion, and triazolam in d-amphetamine-trained humans. Exp Clin Psychopharmacol. 1998;6:32-44.

102. Rush CR, Essman WD, Simpson CA, Baker RW. Reinforcing and subject-rated effects of methylphenidate and d-amphetamine in non-drug-abusing humans. J Clin Psychopharmacol. 2001;21: 273-286.

103. Schmid Y, Hysek CM, Simmler LD, Crockett MJ, Quednow BB, Liechti ME. Differential effects of MDMA and methylphenidate on social cognition. J Psychopharmacol. 2014;28:847-856.

104. Rush CR, Baker RW. Behavioral pharmacological similarities between methylphenidate and cocaine in cocaine abusers. Exp Clin Psychopharmacol. 2001;9:59-73.

105. Stoops WW, Glaser PE, Rush CR. Reinforcing, subject-rated, and physiological effects of intranasal methylphenidate in humans: a dose-response analysis. Drug Alcohol Depend. 2003;71:179-186.

106. Wang GJ, Volkow ND, Hitzemann RJ, et al. Behavioral and cardiovascular effects of intravenous methylphenidate in normal subjects and cocaine abusers. Eur Addict Res. 1997;3:49-54.

107. Roache JD, Grabowski J, Schmitz JM, Creson DL, Rhoades HM. Laboratory measures of methylphenidate effects in cocaine-dependent patients receiving treatment. J Clin Psychopharmacol. 2000;20: 61-68.
108. Khantzian EJ, Gawin F, Kleber HD, Riordan CE. Methylphenidate (Ritalin) treatment of cocaine dependence - a preliminary report. J Subst Abuse Treat. 1984;1:107-112.

109. Imbert B, Labrune N, Lancon C, Simon N. Use of extended-release methylphenidate (concerta) in treatment of cocaine dependence in a patient presenting with attention deficit hyperactivity disorder. J Neuropsychiatry Clin Neurosci. 2014;26:E49-E50.

110. Mariani JJ, Khantzian EJ, Levin FR. The self-medication hypothesis and psychostimulant treatment of cocaine dependence: an update. $\mathrm{Am}$ J Addict. 2014;23:189-193.

111. Gawin F, Riordan C, Kleber H. Methylphenidate treatment of cocaine abusers without attention deficit disorder: a negative report. Am J Drug Alcohol Abuse. 1985;11:193-197.

112. Levin FR, Evans SM, McDowell DM, Kleber HD. Methylphenidate treatment for cocaine abusers with adult attention-deficit/hyperactivity disorder: a pilot study. J Clin Psychiatry. 1998;59:300-305.

113. Castaneda R, Sussman N, Levy R, Trujillo M. A treatment algorithm for attention deficit hyperactivity disorder in cocaine-dependent adults: a one-year private practice study with long-acting stimulants, fluoxetine, and bupropion. Subst Abus. 1999;20:59-71.

114. Somoza EC, Winhusen TM, Bridge TP, et al. An open-label pilot study of methylphenidate in the treatment of cocaine dependent patients with adult attention deficit/hyperactivity disorder. $J$ Addict Dis. 2004;23:77-92.

115. Szobot CM, Shih MC, Schaefer T, et al. Methylphenidate DAT binding in adolescents with attention-deficit/hyperactivity disorder comorbid with substance use disorder - a single photon emission computed tomography with $[\mathrm{Tc}(99 \mathrm{~m})]$ TRODAT-1 study. Neuroimage. 2008;40:1195-1201.

116. Schubiner H. Substance abuse in patients with attention-deficit hyperactivity disorder : therapeutic implications. CNS Drugs. 2005;19: 643-655.

117. Levin FR, Evans SM, Brooks DJ, Kalbag AS, Garawi F, Nunes EV. Treatment of methadone-maintained patients with adult ADHD double-blind comparison of methylphenidate, bupropion and placebo. Drug Alcohol Depend. 2006;81:137-148.

118. Levin FR, Evans SM, Brooks DJ, Garawi F. Treatment of cocaine dependent treatment seekers with adult ADHD: double-blind comparison of methylphenidate and placebo. Drug Alcohol Depend. 2007;87:20-29.

119. Czoty PW, Martelle SE, Gould RW, Nader MA. Effects of chronic methylphenidate on cocaine self-administration under a progressiveratio schedule of reinforcement in rhesus monkeys. J Pharmacol Exp Ther. 2013;345:374-382.

120. Tiihonen J, Kuoppasalmi K, Föhr J, et al. A comparison of aripiprazole, methylphenidate, and placebo for amphetamine dependence. $\mathrm{Am} \mathrm{J}$ Psychiatry. 2007;164:160-162.

121. Martinez D, Carpenter KM, Liu F, et al. Imaging dopamine transmission in cocaine dependence: link between neurochemistry and response to treatment. Am J Psychiatry. 2011;168:634-641.

122. Goldstein RZ, Volkow ND. Oral methylphenidate normalizes cingulate activity and decreases impulsivity in cocaine addiction during an emotionally salient cognitive task. Neuropsychopharmacology. 2011;36:366-367.

123. Goldstein RZ, Woicik PA, Maloney T, et al. Oral methylphenidate normalizes cingulate activity in cocaine addiction during a salient cognitive task. Proc Natl Acad Sci U S A. 2010;107: 16667-16672.

124. Konova AB, Moeller SJ, Tomasi D, Volkow ND, Goldstein RZ. Effects of methylphenidate on resting-state functional connectivity of the mesocorticolimbic dopamine pathways in cocaine addiction. JAMA Psychiatry. 2013;70:857-868.

125. Matuskey D, Luo X, Zhang S, et al. Methylphenidate remediates error-preceding activation of the default mode brain regions in cocaineaddicted individuals. Psychiatry Res. 2013;214:116-121.

126. Volkow ND, Wang GJ, Tomasi D, et al. Methylphenidate attenuates limbic brain inhibition after cocaine-cues exposure in cocaine abusers. PLoS One. 2010;5:e11509. 
127. Haile CN, Kosten TR. The potential of pharmacogenomics to treat drug addiction. Pharmacogenomics. 2009;10:1883-1886.

128. Kosten TR, Wu G, Huang W, et al. Pharmacogenetic randomized trial for cocaine abuse: disulfiram and dopamine $\beta$-hydroxylase. Biol Psychiatry. 2013;73:219-224.

129. DeVito EE, Babuscio TA, Nich C, Ball SA, Carroll KM. Gender differences in clinical outcomes for cocaine dependence: randomized clinical trials of behavioral therapy and disulfiram. Drug Alcohol Depend. 2014;145:156-167.
130. Anker JJ, Carroll ME. Females are more vulnerable to drug abuse than males: evidence from preclinical studies and the role of ovarian hormones. In: Neill JC, Kulkarni J, editors. Biological Basis of Sex Differences in Psychopharmacology. Heidelberg: Springer-Verlag Berlin Heidelberg; 2011:73-96.

\section{Publish your work in this journal}

Substance Abuse and Rehabilitation is an international, peer-reviewed, open access journal publishing original research, case reports, editorials, reviews and commentaries on all areas of addiction and substance abuse and options for treatment and rehabilitation. The manuscript management system is completely online and includes a very quick and fair peer-review system. Visit http://www.dovepress.com/testimonials.php to read real quotes from published authors. 